\title{
RESEARCH
}

Open Access

\section{The impact of pregnancy induced hypertension on low birth weight in Ethiopia: systematic review and meta- analysis}

Temesgen Getaneh $^{1 *} \mathbb{B}$, Ayenew Negesse ${ }^{2,3}$, Getenet Dessie ${ }^{4}$ and Melaku Desta ${ }^{1}$

\begin{abstract}
Background: Even though neonatal mortality reduction is the major goal needed to be achieved by 2030, it is still unacceptably high especially in Ethiopia. In the other hand, low birth weight is the major cause of neonatal mortality and morbidity. More than 10 millions of low birth weight infants occurred as a result of pregnancy induced hypertension. However, in Ethiopia the association between low birth weight and pregnancy induced hypertension was represented with un-updated, inconclusive and different studies. Therefore, this review aimed to estimate the overall pooled impact of pregnancy induced hypertension on low birth weight and its association in Ethiopia.
\end{abstract}

Methods: articles searched on PubMed/Medline, EMBASE, CINAHL, Cochrane library, Google, Google Scholar and local shelves. Joanna Briggs Institute Meta-Analysis of Statistics Assessment and Review Instrument (JBI-MAStARI) was applied for critical appraisal. The $P^{2}$ statistic was computed to check the presence of heterogeneity. Publication bias was evaluated using funnel plot asymmetry and Egger's test. A random effect model was used to estimate the pooled prevalence of low birth weight.

Result: From the total 131 identified original articles, 25 were eligible and included for the final analysis. The overall pooled prevalence of low birth weight among women who had pregnancy induced hypertension in Ethiopia was 39.7\% (95\% Cl: 33.3, 46.2). But, $P^{2}$ statistic estimation evidenced significant heterogeneity across included studies $\left(I^{2}=89.4, p<0.001\right)$. In addition, the odds of having low birth weight newborns among women who had pregnancy induced hypertension was 3.89 times higher compared to their counterparts ( $\mathrm{OR}=3.89,95 \% \mathrm{Cl}: 2.66,5.69)$.

Conclusion: The pooled prevalence of low birth weight among women who had pregnancy induced hypertension was more than two times higher than the pooled estimate of low birth weight among all reproductive aged women. The odds of low birth weight also increased nearly four times among women with pregnancy induced hypertension than normotensive women. Therefore, health policies which provide better and quality antenatal care with more oriented on importance of early detection and management of pregnancy induced hypertension should be implemented.

Keywords: Low birth weight, Pregnancy induced hypertension, Ethiopia

* Correspondence: temugetaneh@gmail.com

'Department of Midwifery, College of Health Science, Debre Markos University, P.O. Box 269, Debre Markos, Ethiopia

Full list of author information is available at the end of the article

C The Author(s). 2020 Open Access This article is licensed under a Creative Commons Attribution 4.0 International License, which permits use, sharing, adaptation, distribution and reproduction in any medium or format, as long as you give appropriate credit to the original author(s) and the source, provide a link to the Creative Commons licence, and indicate if changes were made. The images or other third party material in this article are included in the article's Creative Commons licence, unless indicated otherwise in a credit line to the material. If material is not included in the article's Creative Commons licence and your intended use is not permitted by statutory regulation or exceeds the permitted use, you will need to obtain permission directly from the copyright holder. To view a copy of this licence, visit http://creativecommons.org/licenses/by/4.0/. The Creative Commons Public Domain Dedication waiver (http://creativecommons.org/publicdomain/zero/1.0/) applies to the data made available in this article, unless otherwise stated in a credit line to the data. 


\section{Background}

According to the World Health Organization (WHO), Low birth weight (LBW) is defined as a birth weight of less than $2500 \mathrm{~g}$ irrespective of the gestational age. It is an important marker of maternal and fetal health and nutrition [1]. Globally, LBW is estimated that $15 \%$ of all births are LBW, representing more than 20.5 million births a year [2]. The great majority of LBW births occur in low and middle income countries [3]. Especially, Africa is home to about one quarter of all LBW newborns, sub-Saharan Africa contribute for 13\% of LBW [4]. In Ethiopia, about $13 \%$ of newborns are LBW according to Ethiopian Demographic and Health Survey 2016 [5]. Nevertheless, LBW is a global concern, as some highincome countries are also faced with high rates for their contexts [6].

LBW is a significant public health problem, frequently associated with neonatal and child morbidity and mortality [7]. LBW newborn had higher risk of dying in the first 28 days of life [8]. In Ethiopia, more than $4.5 \%$ of neonatal mortality was due to LBW [9]. It is also associated with morbidities including stunting, metabolic syndrome, cardiovascular disorder, chronic renal insufficiency, diabetes mellitus and obesity [10]. LBW also showed significant effects on poor cognitive development, school performance and behavioral outcomes later in life [11, 12]. Moreover, LBW contributes to the costs to the family, society and the country as a whole. Neonatal hospital costs are high and it remains high after hospital discharge as children grow older costs continues to be high [13].

Globally, maternal nutrition, extreme maternal age, socio-economic status, multiple pregnancies, chronic medical conditions and pregnancy induced hypertension (PIH) are the common causes of LBW [14-17]. PIH is a significant public health threat and cause of neonatal morbidity and mortality especially in developing countries, accounting for more than 10 million LBW infants $[18,19]$. In adding to this, women who had PIH were nearly ten times at increased risk of LBW [20].

Decreased utero-placental perfusion also significantly increases the risk of intrauterine growth restriction, preterm birth and other neonatal comorbidities (like respiratory distress syndrome, intraventricular hemorrhage) and other systemic disturbances [21, 22]. In addition, these children are more susceptible to neurodevelopmental and behavioral problems as well as chronic noncommunicable disease later in life [12, 23, 24]. In Ethiopia, the burden of PIH ranges from 2.23 to $18.25 \%$ [25, 26]. So, LBW is a complex syndrome that includes preterm neonates, small for gestational age neonates and the overlap between these two situations, typically have the worst outcomes [27]. In addition, PIH also responsible for nearly one tenth of maternal mortality in middle and low income countries and one-fifth maternal mortality Ethiopia [28].
Reduction in LBW mortality have greatly contribute to the reduction in overall mortality and recognized as a public health priority. World Health Assembly Member States endorsed the target of 30\% reduction in LBW globally in 2025 [29]. However, the world is still far from achieving this objective. So, reporting such a comprehensive finding, the effect of PIH on LBW, will have great role to achieve LBW reduction which was one of the major causes of neonatal morbidity and mortality. In a country like Ethiopia where striving to reduce neonatal mortality in 2030, investigating such concrete scientific evidence will be a major input for future neonatal health and outcome improvement.

In Ethiopia, several individual studies were done and reported inconsistent findings in the relationship between PIH and LBW, except one review published in 2019 which didn't include all currently available researches on association of PIH and LBW (studies done after the previous review) [30]. Accordingly, the prevalence of LBW among PIH women ranges from 9.8\% [31] to $64.4 \%$ [32]. In addition, the odds of developing LBW among women who had PIH range from 1.31 to 10.33 [20,33]. Therefore, the aim of this systematic review and meta analysis was to estimate an updated pooled prevalence of LBW among women who had PIH and their association in Ethiopia. It is envisaged that results of this study could contribute to achieve reduction of LBW (and in turn neonatal morbidity and mortality) globally, especially in middle and low income countries including Ethiopia.

\section{Methodology}

\section{Searching strategies}

Initially, systematic review and meta analysis including registered protocols were searched to avoid duplication. Accordingly, there was one systematic review reported on adverse neonatal outcomes of PIH, which was not primary focused on LBW and different search strategies lead to evaluate different researches. In addition, there are studies published after the previous review published. Published articles were systematically searched using major databases: PubMed/Medline, EMBASE, CINAHL, Cochrane library, Google and Google Scholar. In addition to this, the reference lists of already identified articles, grey literature available on local shelves and institutional repositories were used to access unidentified and un-published articles. All articles published till June 11/2020 were included in this systematic review and meta analysis. All fields, MeSH terms and key terms combined with Boolean operators were used to search articles in electronics data bases and advanced PubMed search. The key terms used for searching were "infant" OR "neonatal" OR "child" AND "LBW" OR "abnormal weight" OR "birth weight" OR "very low birth weight" 
OR "adverse outcomes" OR "underweight" OR "birth outcome" AND "PIH" OR "preeclampsia" OR "gestational hypertension" AND "Ethiopia". Then identified articles were exported into endnote citation manager software version X7 for Windows to exclude duplicate records. This review is reporting in accordance with the Preferred Reporting Items for Systematic Reviews and Meta-Analyses Protocols (PRISMA) checklist guidelines [34] (see Additional file 1).

\section{Eligibility criteria \\ Inclusion criteria}

All studies conducted in all regional state and city of Ethiopia on reproductive aged women that reported; either the prevalence of newborn birth weight among women who had PIH or the association between PIH and neonatal birth or both were considered for this systematic review and meta analysis. In order to estimate the pooled prevalence, only women who had PIH were included while for estimating the association, both normotensive and hypertensive women were considered. Articles considered PIH as a general or specifically either gestational hypertension or preeclampsia or eclampsia were considered. There was no restriction applied in terms of type of PIH, language, study design, sampling technique, study area, study year and publication year.

\section{Exclusion criteria}

All identified studies titles and abstracts were screened for eligibility criteria of the review by reviewers independently. According to selection criteria, full texts of eligible studies were examined. Those papers which did not fully accessed at the time of our search process were excluded after contact was attempted with the principal investigator through email at least two times. Finally, after reviewing their full texts, studies which did not report our outcome of interest and studies with poor quality as per settled criteria of reviewing the articles were excluded from the final analysis.

\section{Data extraction}

After standardized data extraction format developed according to 2014 Joanna Briggs Institute Reviewers' Manual [35], two authors (TG and AN) extract the data using the spread sheet. The developed data extraction format include: study of region, publication year, study design and technique, type of PIH, sample size, mean age of respondent and prevalence as well as the cross tabulation of their association.

\section{Quality assessment}

Joanna Briggs Institute Meta-Analysis of Statistics Assessment and Review Instrument (JBI-MAStARI) [36] was utilized for critical appraisal of included studies before data extraction. The criteria used for cohort studies includes: 1.study population recruited from the same population, 2.exposures measured similarly to assign people to both groups, 3.valid and reliable measurement for exposure, 4.confounding factors identified, 5.strategies to deal confounding factors, 6.the participants free of the outcome at the start of the study, 7.valid and reliable measurement for outcomes, 8.sufficient follow up time, follow up complete (or reasons to loss to follow up), 9.strategies to address incomplete follow up utilized and 10.appropriate statistical analysis used.

Whereas for case control studies includes: 1.comparable groups, 2.cases and controls matched appropriately, 3.similar criteria used for identification of cases and controls, 4.valid and reliable measurement for exposure, 5.similar exposure measurement, 6.confounding factors identified, 7.strategies to deal with confounding factors, 8.outcomes assessed in valid and reliable way, 9.the exposure period of interest long enough and 10.appropriate statistical analysis used and for cross sectional studies includes: 1.the criteria for inclusion in the sample clearly defined, 2.the study subjects and the setting described in detail, 3.valid and reliable measurement for exposure, 4.standard criteria used for measurement of the condition, 5.confounding factors identified, 6.strategies to deal with confounding factors stated, 7.the outcomes measured in a valid and reliable way and 8.appropriate statistical analysis used. Each individual paper were critically evaluated by two independent reviewers. Disagreements between the reviewers were resolved via consensus. If not third reviewer was involved to resolve inconsistencies in between the two independent reviewers. After quality assessment, studies which scored five and above were included in this review.

\section{Outcome measurement}

The outcome of this systematic review and meta analysis was the prevalence of LBW among women who had PIH. LBW is defined as a birth weight of less than 2500 $\mathrm{g}$ irrespective of the gestational age.

\section{Data analysis}

First, the extracted data computed in excel spread sheet were imported to STATA version 14 for further analysis. Forest plot was computed to show the pooled prevalence of LBW and heterogeneity. Cochran's Q statistic with inverse variance $\left(\mathrm{I}^{2}\right)$ were used to assess the existence of statistical heterogeneity and to quantify it. Low, moderate and high heterogeneity were considered at 25, 50 and $75 \%$ respectively (23). In addition, $p$ value less than 0.05 was used to confirm the presence of heterogeneity across studies. Also, publication bias was assessed using Egger's regression test [37] using $p$ value less than 0.05 as a cut point to declare the presence of publication bias 
and used a funnel plot to represent graphically the bias. The estimated pooled prevalence of LBW was presented using forest plot diagram with their corresponding 95\% $\mathrm{CI}$ and OR. Finally, subgroup analysis and meta regression were computed to explore those potential heterogeneity across studies.

\section{Results}

\section{Explanation of original studies}

A total of 131 articles were retrieved from electronic data bases and gray literatures related to association between LBW and PIH in Ethiopia. Then, 44 articles were excluded because of duplication. From the remaining, 61 articles were removed as reason of irrelevance of titles to this review. Out of these, after reviewing the remaining studies, one article was excluded because of inaccessibility of full text (difficult to assess the quality of this paper without full document) [38]. Finally 25 articles were eligible and considered for this systematic review (Fig. 1).

Based on our inclusion criteria, only 25 articles were included and considered for final analysis. From those included studies, eight articles were done in Amhara region [20, 32, 33, 39-43], seven in SNNP [31, 44-49], four articles in AA [50-53] and Oromo [25, 54-56] for each and one article in Tigray [57] and Ethiopian Somalia region [58] for each. Concerning to publication, one study was un-published (grey literature) [40] whereas the remaining 24 articles were published from 2005 to 2020 in different journals [20, 25, 31-33, 39, $41-50,52,53,55-58]$. Regarding to study design, 15 articles were employed cross sectional [20, 25, 31, 39, 41$43,47-51,53-56]$ while the five studies were done using cohort $[33,45,50,57,58]$ and case control design [32, $40,44,46,52]$ for each studies scored five and above out of settled criteria for each study design according to JBI critical appraisal were included for this systematic review and meta analysis (Table 1).

\section{Pooled prevalence of LBW among women who had PIH in Ethiopia}

The pooled prevalence LBW among women who had PIH in Ethiopia was range from 33.3 to $46.2 \%$ whereas the point estimate of the pooled prevalence of LBW among PIH women was 39.77\% (95\% CI: 33.33, 46.22). In this review, $I^{2}$ test statistics showed a significant level of heterogeneity across included studies $\left(I^{2}=89.4 \%, p<\right.$ 0.001) (Fig. 2). Therefore, to estimate the pooled prevalence of LBW and its association between LBW and $\mathrm{PIH}$, random effect model was indicated. In addition, subgroup analysis and meta-regression were computed to estimate the pooled prevalence of LBW among

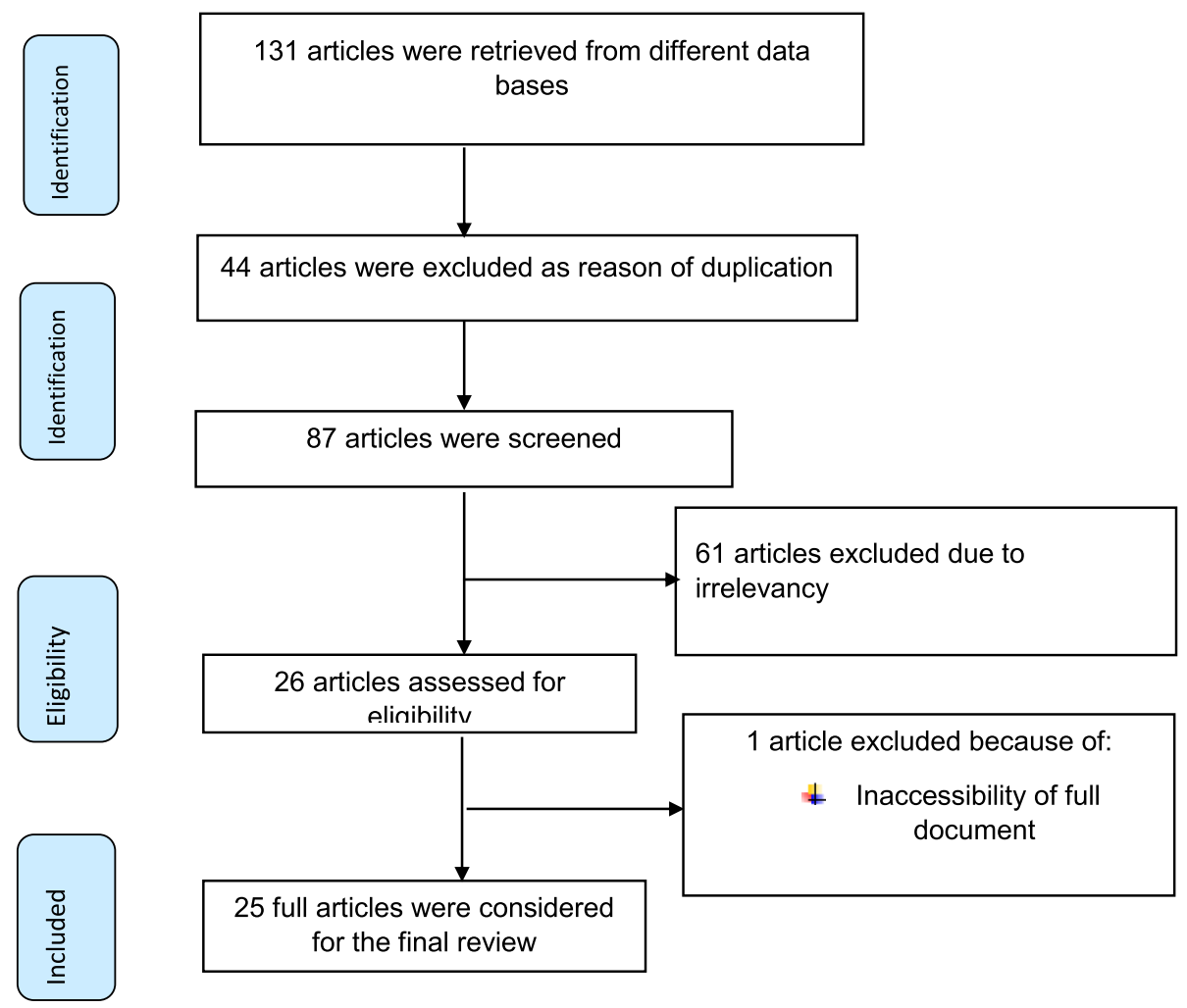

Fig. 1 PRISMA flow diagram of included studies to estimate the effect of PIH on LBW prevalence in Ethiopia: 2005-2020 
Table 1 Descriptive summary of included studies in this systematic review and meta-analysis to assess association of LBW and PIH in Ethiopia

\begin{tabular}{|c|c|c|c|c|c|c|c|c|c|}
\hline Author & $\begin{array}{l}\text { Study } \\
\text { Year }\end{array}$ & Region & $\begin{array}{l}\text { Study } \\
\text { design }\end{array}$ & $\begin{array}{l}\text { Sampling } \\
\text { technique }\end{array}$ & $\begin{array}{l}\text { Mean } \\
\text { age }\end{array}$ & $\begin{array}{l}\text { Type } \\
\text { of PIH }\end{array}$ & $\begin{array}{l}\text { Sample } \\
\text { size }\end{array}$ & $\begin{array}{l}\text { Prevalence } \\
(\%)\end{array}$ & $\begin{array}{l}\text { JBI } \\
\text { score }\end{array}$ \\
\hline Wagnew et al [53] & 2016 & $\mathrm{AA}$ & Cross-sectional & Consecutive & 26.75 & $\mathrm{PIH}$ & 1809 & 44.2 & 6 \\
\hline Seyom et al [54] & 2015 & Oromo & Cross-sectional & Consecutive & 24.4 & $\mathrm{PIH}$ & 121 & 31 & 5 \\
\hline Melese et al [42] & 2018 & Amhara & Cross-sectional & Consecutive & 28.3 & $\mathrm{PIH}$ & 456 & 13 & 7 \\
\hline Asseffa et al [31] & 2019 & SNNP & Cross-sectional & Consecutive & 25.4 & $\mathrm{PIH}$ & 168 & 9.8 & 6 \\
\hline Gudeta et al [55] & 2017 & Oromo & Cross-sectional & SYRS & - & $\mathrm{PIH}$ & 33 & 24.2 & 7 \\
\hline Jima A et al [50] & 2014 & AA & Cohort & Consecutive & - & Eclampsia & 78 & 61.5 & 6 \\
\hline Obsa et al [49] & 2018 & SNNP & Cross-sectional & Consecutive & & $\mathrm{PIH}$ & 225 & 28.8 & 5 \\
\hline Berhe et al [57] & 2020 & Tigray & Cohort & Consecutive & 27.34 & $\mathrm{PIH}$ & 260 & 37.7 & 8 \\
\hline Gudu et al [58] & 2018 & Somalia & Cohort & Consecutive & 23 & Eclampsia & 75 & 45.3 & 7 \\
\hline Wolde et al [56] & 2011 & Oromo & Cross-sectional & Consecutive & - & $\mathrm{PIH}$ & 146 & 41.09 & 5 \\
\hline Vata et al [25] & 2015 & Oromo & Cross-sectional & Consecutive & - & $\mathrm{PIH}$ & 172 & 26.74 & 6 \\
\hline Terefe et al [43] & 2015 & Amhara & Cross-sectional & Consecutive & 25.4 & $\mathrm{PIH}$ & 226 & 39.4 & 6 \\
\hline Kebede et al [33] & 2013 & Amhara & Cohort & Consecutive & 27.27 & Eclampsia & 14 & 28.57 & 6 \\
\hline Girma et al [51] & 2018 & $\mathrm{AA}$ & Cross-sectional & SYRS & - & $\mathrm{PIH}$ & 105 & 39.04 & 6 \\
\hline Desalegn et al & Un-pu & Amhara & case control & Consecutive & - & $\mathrm{PIH}$ & 34 & 47 & 5 \\
\hline Bekela et al [44] & 2020 & SNNP & case control & Consecutive & & $\mathrm{PIH}$ & 57 & 49.12 & 7 \\
\hline Adane et al [39] & 2014 & Amhara & Cross-sectional & Consecutive & 26.2 & $\mathrm{PIH}$ & 19 & 36.8 & 6 \\
\hline Lake et al [48] & 2019 & SNNP & Cross-sectional & SYRS & 25 & $\mathrm{PIH}$ & 33 & 48.5 & 6 \\
\hline Mulu et al [52] & 2020 & $\mathrm{AA}$ & Case control & SYRS & - & $\mathrm{PIH}$ & 56 & 50 & 7 \\
\hline Ekubagewargies et al [41] & 2019 & Amhara & Cross-sectional & SRS & 27.1 & $\mathrm{PIH}$ & 31 & 25.08 & 7 \\
\hline Desta et al [49] & 2019 & SNNP & Cohort & SYRS & 26.9 & $\mathrm{PIH}$ & 64 & 40.62 & 7 \\
\hline Zenebe et al [20] & 2014 & Amhara & Cross-sectional & SYRS & 25.8 & $\mathrm{PIH}$ & 28 & 64.28 & 6 \\
\hline Gebremariam et al [47] & 2005 & SNNP & Cross-sectional & SRS & - & $\mathrm{PIH}$ & 24 & 62.5 & 5 \\
\hline Gebrehawarya et al [32] & 2018 & Amhara & Case control & Consecutive & 24.5 & $\mathrm{PIH}$ & 45 & 64.4 & 7 \\
\hline Egata et al [46] & 2019 & SNNP & Case control & Consecutive & - & $\mathrm{PIH}$ & 396 & - & 5 \\
\hline
\end{tabular}

women who had PIH and to identify potential source of heterogeneity using different study characteristics.

\section{Subgroup analysis}

As stated above, this systematic review showed significant heterogeneity across included studies. So, subgroup analysis was done using region, publication year, study design, sampling technique and type of PIH. Regarding to regional prevalence, in Addis Ababa (AA) almost half of women who had PIH delivered LBW newborns (48.5 95\% CI: 39, 57). Whereas in Amhara and SNNP, more than one third of newborns born from women who had PIH were LBW (39.6 95\% CI: 26, 42 and 39.7\% (95\% CI: 22, 56 respectively). In Oromo region, 30.5\% (95\% CI: $23,57)$ of newborns born from women with PIH experienced LBW.

Regarding to study design, studies done using case control design reported more than half of newborn babies born from women who had PIH had LBW (52.5\%:
95\% CI: 44, 60). While studies done in cohort and cross sectional indicated $42.59 \%$ (95\% CI: 32, 52) and 35.44\% (95\% CI: 27, 43) of pooled prevalence of LBW among $\mathrm{PIH}$ women respectively. Ones more, studies which evaluate effect on PIH as general on LBW reported pooled prevalence of $39.03 \%$ (95\% CI: 32, 45) and studies which taken effect of eclampsia on LBW indicated $45 \%$ (95\% CI: 26,63 ) of pooled prevalence of LBW (Table 2).

\section{Meta regression}

As we have mentioned before, the forest plot detected statistically significant heterogeneity. So, in order to identify those potential source of heterogeneity, metaregression was done using both continuous and categorical study characteristics: including publication year, sample size, mean age of the women, region, type of $\mathrm{PIH}$, study design and technique. But, none of these variables were found to be statistically significant as shown below (Table 3). 


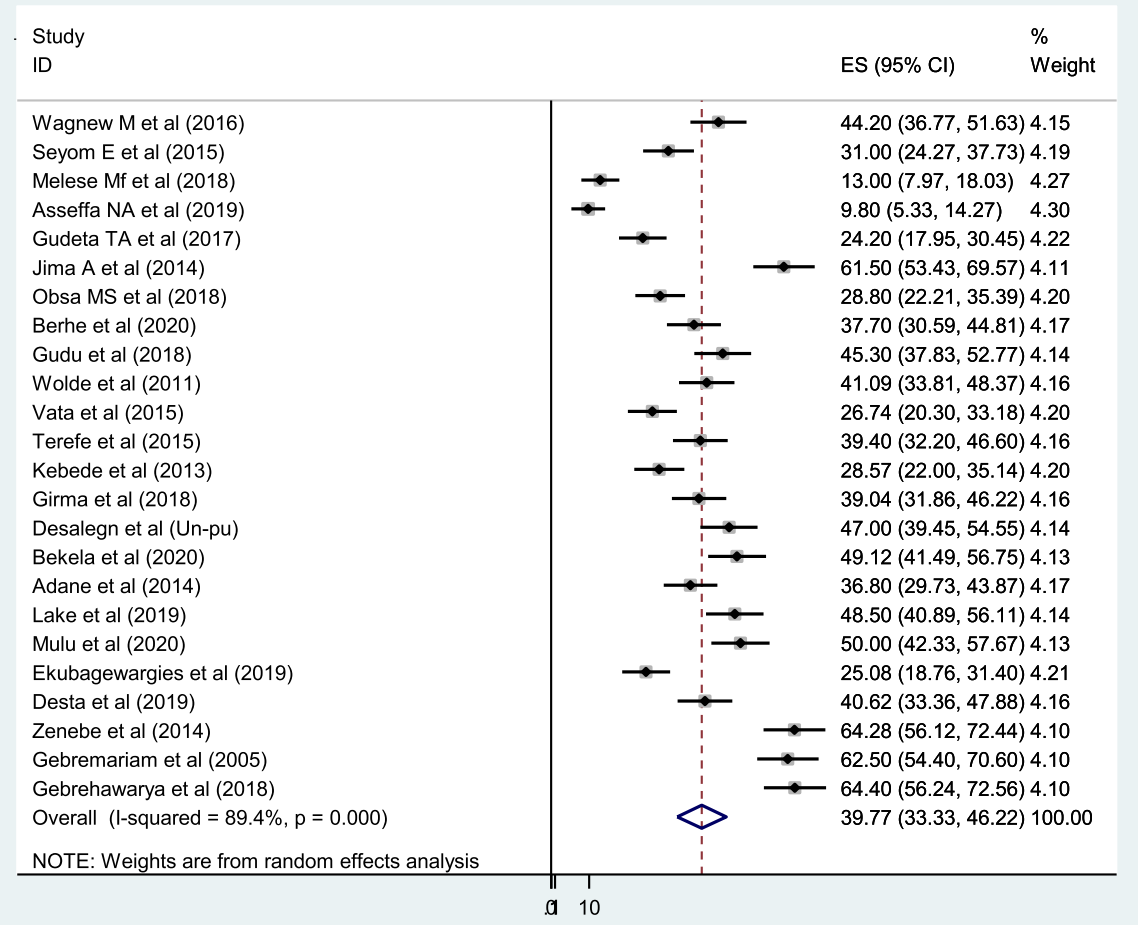

Fig. 2 Forest plot of the pooled prevalence of LBW among women who had PIH in Ethiopia: 2005-2020

Furthermore, symmetric funnel plot and Egger's tests were undertaken to assess publication bias. All of them confirmed publication bias was not observed, evidenced with the following symmetric funnel plot (Fig. 3), Egger's test $p$-value $=0.304(95 \%$ CI: $-0.061,0.186)$.

\section{The impact of pregnancy induced hypertension on low birth weight}

In addition to estimating the pooled prevalence of LBW among women who had PIH, this meta analysis also evaluate the odds of association between LBW and PIH. Accordingly, the odds of LBW among women who had diagnosed PIH was 3.89 times higher when compared with normotensive women $(\mathrm{OR}=3.89,95 \% \mathrm{CI}$ : 2.66 , 5.69) (Fig. 4).

\section{Discussion}

Generally, the main aim of this systematic review and meta-analysis was to estimate the pooled prevalence of LBW among women who had PIH and to evaluate the impact of PIH on LBW in Ethiopia. Reduction of neonatal mortality is one of the major Sustainable Developmental Goals needed to be achieved by 2030 worldwide. But, neonatal mortality is still unacceptably high. Specifically in Ethiopia, the Mini Ethiopian Demographic Health Survey 2019 reported that neonatal mortality was still sustained [59] and LBW is one of the major causes of neonatal mortality. So, in a country like Ethiopia where striving to reduce neonatal mortality in 2030, investigating such concrete scientific evidence will be used as indicator for maternal and child health cares and input for health policy, programmers and implementers to improve neonatal health.

This review showed that, more than one-third of neonates born from women who had PIH were LBW. The pooled prevalence ranges from 33.3 to $46.2 \%$ with average estimate of $39.7 \%$. This finding is in line with studies conducted in India [60], Uganda [61], Zimbabwe [62], Egypt [63] and systematic review done in Ethiopia [30]. This the finding is lower than studies done in Bangladesh [64], Tanzania [65] and Sudan [66]. However, it is higher than result of secondary analysis of the WHO multi-country survey done on 29 countries from Africa, Asia, Latin America and the Middle East [67]. In addition, this figure is almost two times higher than studies conducted in Malaysia [68] and Ghana [69]. This could be due to the difference in prevalence of PIH across countries and socioeconomic factors as well as attributed to difference in health facility characteristics such as service provision and diagnostics capability.

Furthermore, this figure is more than two times higher than the pooled estimate of LBW among the total 
Table 2 Sub group analysis which describes pooled prevalence of LBW among women who had PIH with different study characteristics in Ethiopia: 2005-2020

\begin{tabular}{|c|c|c|c|c|c|c|}
\hline Subgroup & & No of studies & prevalence $(95 \% \mathrm{Cl})$ & Heterogeneity statistics & $\mathrm{I}^{2}$ & $p$-value \\
\hline \multirow[t]{5}{*}{ Region } & Amhara & 8 & $39.64(26,52)$ & 197.34 & 96.5 & $<0.001$ \\
\hline & AA & 4 & $48.56(39,57)$ & 17.99 & 83.3 & $<0.001$ \\
\hline & SNNPR & 6 & $39.74(22,56)$ & 192.71 & 97.4 & $<0.001$ \\
\hline & Oromo & 4 & $30.58(23,37)$ & 13.29 & 77.4 & 0.004 \\
\hline & Others & 2 & $41.41(33,48)$ & 2.08 & 52 & 0.149 \\
\hline \multirow[t]{3}{*}{ Publication year } & Before 2016 & 9 & $43.38(33,52)$ & 125.6 & 93.6 & $<0.001$ \\
\hline & 2016 \& above & 14 & $36.95(28,45)$ & 314.13 & 95.9 & $<0.001$ \\
\hline & Un-published & 1 & $49(39,54)$ & 0.0 & - & - \\
\hline \multirow[t]{3}{*}{ Study design } & Cross sectional & 15 & $35.44(27,43)$ & 319.85 & 95.5 & $<0.001$ \\
\hline & Cohort & 5 & $42.59(32,52)$ & 40.59 & 90.1 & $<0.001$ \\
\hline & Case control & 4 & $52.51(44,60)$ & 11.35 & 73.6 & 0.010 \\
\hline \multirow[t]{3}{*}{ Sampling technique } & Consecutive & 16 & $37.60(29,45)$ & 336.15 & 94.6 & $<0.001$ \\
\hline & Systematic sampling & 6 & $44.29(33,53)$ & 67.56 & 92.6 & $<0.001$ \\
\hline & Simple random & 2 & $43.70(7,80)$ & 50.95 & 98 & $<0.001$ \\
\hline \multirow[t]{2}{*}{ Type of hypertension } & $\mathrm{PlH}$ & 16 & $39.03(32,45)$ & 434.68 & 95.4 & $<0.001$ \\
\hline & Eclampsia & 3 & $45(26,63)$ & 39.06 & 94.9 & $<0.001$ \\
\hline
\end{tabular}

population in Ethiopia [70]. The difference may be due to our review included only studies conducted among women who had PIH, one of the major risk factor for LBW. So, improving the availability, accessibility and quality of maternal health care services is warranted.

In regarding to the association between $\mathrm{LBW}$ and $\mathrm{PIH}$, the odds of LBW among women who had PIH were

Table 3 Meta regression for the included studies to identify source of heterogeneity for the pooled prevalence of LBW among women who had PIH in Ethiopia from 2005 to 2020

\begin{tabular}{lll}
\hline Variables & Coefficients & $\boldsymbol{p}$-value \\
\hline Publication year & -3.055 & 0.226 \\
Sample size & -0.0073 & 0.748 \\
Mean age & -1.637 & 0.743 \\
Region & & \\
AA & 7.13 & 0.589 \\
Amhara & -2.17 & 0.858 \\
Oromo & -10.30 & 0.437 \\
$\quad$ SNNPR & -3.44 & 0.784 \\
Type study design & & \\
$\quad$ Cohort & -8.93 & 0.358 \\
$\quad$ Cross sectional & -18.54 & 0.330 \\
Type sampling technique & & \\
$\quad$ Survey & -5.32 & 0.672 \\
$\quad$ Systematic random & 1.39 & 0.918 \\
Pregnancy induced hypertension & -9.18 & 0.351 \\
\hline
\end{tabular}

higher when compared to normotensive women. This finding is in line with WHO secondary analysis survey conducted in low and middle income countries, which confirmed that the risk of acquiring LBW among women with PIH was double [71]. Similarly, studies conducted in United Kingdom [72], China [73] and Malaysia [73] reported that women who had PIH were at higher odds to have LBW newborns. This is also supported by studies held in Haiti [74] and Ghana [69], reported that women who had PIH were two times more likely to have LBW newborn babies. Many studies confirmed that, in $\mathrm{PIH}$ the trophoblast invasion in to the spiral arteries that supply the placenta is incomplete $[75,76]$. Because of decreased utero-placental blood perfusion, leads to small for gestational age, preterm birth and intrauterine growth restriction which end up with LBW [76]. Therefore, provision of timely and effective care to the women presenting with these complications is essential.

Generally, even though still difficulties are there in middle and low income countries including Ethiopia, low dose aspirin and calcium supplementation, prenatal care, timely diagnosis, proper management, timely delivery and comprehensive intensive neonatal care service were very important. But, in Ethiopia, still three out of four women get antenatal care and less than half of them delivered at health facility [59]. So, improvement of maternal and child health services were warranted because $\mathrm{PIH}$ is not only causes neonatal morbidity and mortality but also maternal morbidity and mortality. 


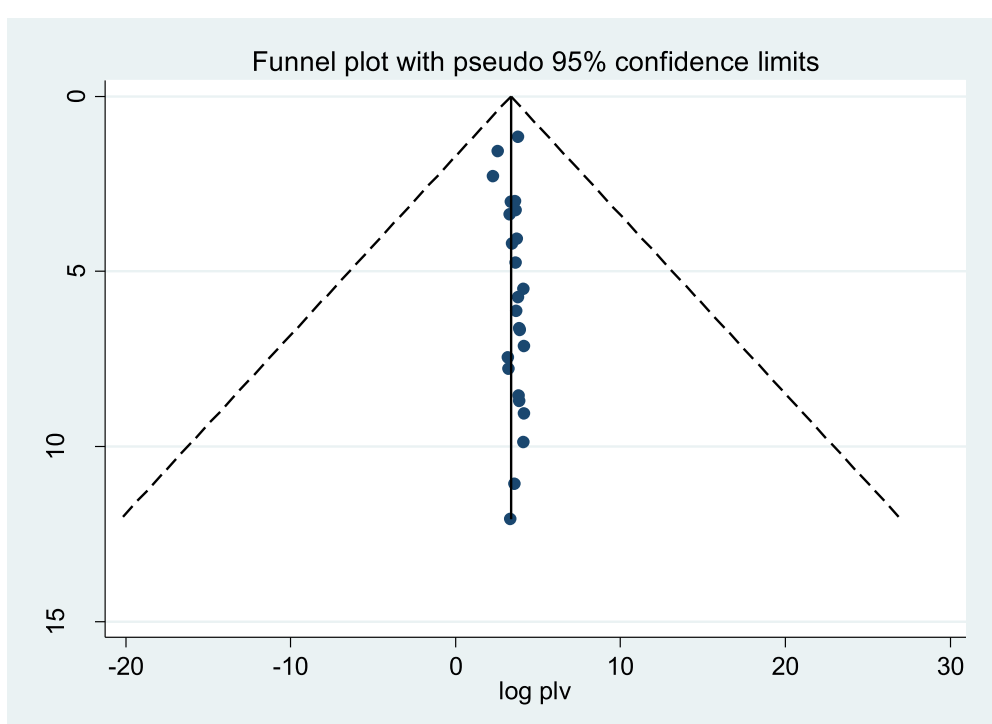

Fig. 3 Meta funnel presentation of the pooled prevalence of LBW among women who had PIH in Ethiopia: 2005-2020

This systematic review and meta analysis is not without limitation. More than half of included articles were cross sectional study design in which the result might potentially affected by confounding variables and difficult to establish temporal relationship. In addition, the meta analysis didn't include all regional states of Ethiopia. Finally, presence of significant statistical heterogeneity among studies was considered as limitation of this review. Therefore, further longitudinal country based studies to assess association of LBW and PIH is recommended.

\section{Conclusion}

This systematic review and meta analysis revealed that, the pooled prevalence of LBW among women who had

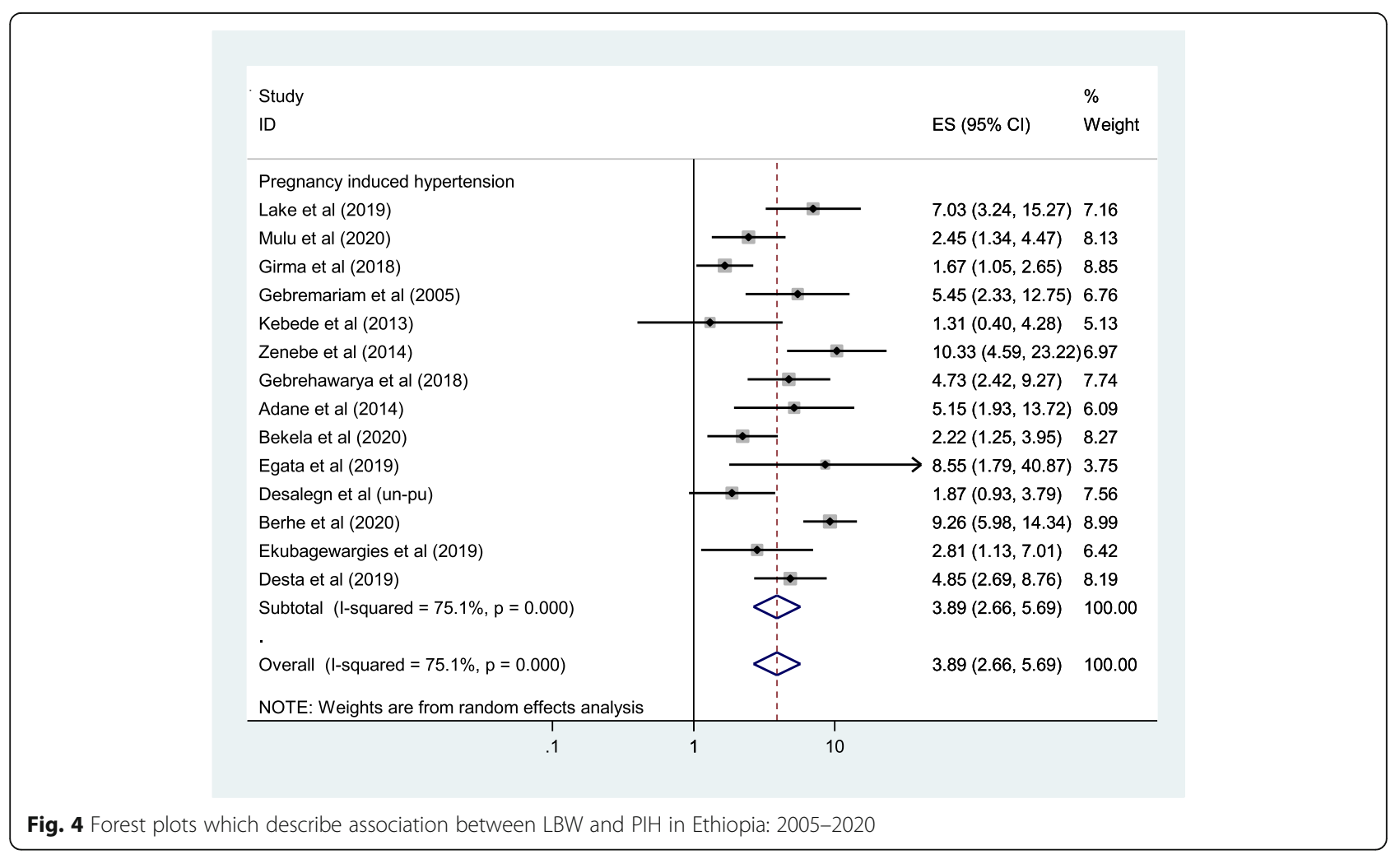


PIH was more than two times higher than the pooled estimate of low birth among general women. The odds of having LBW among women who had PIH was higher when compared with normotensive women. Even though prevention of PIH is difficult, early detection of women at high risk of having PIH coupled with intensive antenatal care and management could prevent the occurrence of this burden of LBW. In addition, improving the availability of antihypertensive therapy and intensive neonatal care service should be addressed. Therefore, enhancing universal access of comprehensive and quality perinatal care and obstetric emergency care services are needed to improve neonatal health in Ethiopia.

\section{Abbreviations}

AA: Addis Ababa; LBW: Low Birth Weight; PIH: Pregnancy Induced Hypertension; SNNP: South Nation and Nationality peoples; WHO: World Health Organization

\section{Acknowledgments}

Not applicable.

\section{Authors' contributions}

TG and AN developed the protocol and involved in the design, selection of study, data extraction, statistical analysis and developing the initial drafts of the manuscript. TG, AN, GD and MD prepared and revising subsequent drafts as well as prepared the final draft of the manuscript. All authors read and approved the final draft of the manuscript.

\section{Funding}

No funding was obtained for this study.

\section{Availability of data and materials}

Data will be available from the corresponding author upon reasonable request.

\section{Ethics approval and consent to participate}

Not applicable.

\section{Consent for publication}

Not applicable.

\section{Competing interests}

The author have declared that there are no competing interests.

\section{Author details \\ ${ }^{1}$ Department of Midwifery, College of Health Science, Debre Markos University, P.O. Box 269, Debre Markos, Ethiopia. ${ }^{2}$ Department of Human Nutrition and Food Sciences, College of Health Science, Debre Markos University, Debre Markos, Ethiopia. ${ }^{3}$ Center of excellence in Human Nutrition, School of Human Nutrition, Food Science and Technology, Hawassa University, Hawasa, Ethiopia. ${ }^{4}$ Department of Nursing, School of Health science, College of Medicine and Health Science, Bahr Dar University, Bahir Dar, Ethiopia.}

Received: 24 June 2020 Accepted: 26 October 2020

Published online: 26 November 2020

\section{References}

1. World Health Organization. Global nutrition targets 2025: Policy brief series. World Health Organization; 2014.

2. World Health Organization. UNICEF-WHO low birthweight estimates: levels and trends 2000-2015. World Health Organization; 2019.

3. Qadir M, Bhutta ZA. Low birth weight in developing countries. InSmall for Gestational Age 2009 (Vol. 13, pp. 148-162). Karger Publishers.
4. Kim D, Saada A. The social determinants of infant mortality and birth outcomes in Western developed nations: a cross-country systematic review. Int J Environ Res Public Health. 2013;10(6):2296-335.

5. Federal Democratic Republic of Ethiopia: Ethiopian demographic and health survey 2016.

6. World Health Organization. Born too soon: the global action report on preterm birth 2012:1-124.

7. Negrato CA, Gomes MB. Low birth weight: causes and consequences. Diabetol Metab Syndr. 2013;5(1):49.

8. Wardlaw TM, editor. Low birthweight: country, regional and global estimates. Unicef; 2004.

9. WHO: World health ranking: Ethiopia low birth weight. 2014.

10. Risnes KR, Vatten $L J$, Baker $J$, Jameson K, Sovio U, Kajantie E, Osler M, Morley R, Jokela M, Painter RC. Birthweight and mortality in adulthood: a systematic review and meta-analysis. Int J Epidemiol. 2011;40(3):647-61.

11. Islam MM. The effects of low birth weight on school performance and behavioral outcomes of elementary school children in Oman. Oman Med J. 2015;30(4):241.

12. Reyes L, Manalich R. Long-term consequences of low birth weight. Kidney Int. 2005;68:S107-11.

13. Petrou S. Economic consequences of preterm birth and low birthweight. BJOG Int J Obstet Gynaecol. 2003;110:17-23.

14. Larroque B, Bertrais S, Czernichow P, Léger J. School difficulties in 20-yearolds who were born small for gestational age at term in a regional cohort study. Pediatrics. 2001;108(1):111-5.

15. Adam Z, Ameme DK, Nortey P, Afari EA, Kenu E. Determinants of low birth weight in neonates born in three hospitals in Brong Ahafo region, Ghana, 2016-an unmatched case-control study. BMC Pregnancy Childbirth. 2019; 19(1):174.

16. Noureddine E, Abdellatif B. Prevalence and determinants of low birth weight: a case-control study in marrakesh (Morocco). Iran J Public Health. 2015:44(3):422.

17. Hailu LD, Kebede DL. Determinants of low birth weight among deliveries at a referral Hospital in Northern Ethiopia. Biomed Res Int. 2018;2018.

18. Backes CH, Markham K, Moorehead P, Cordero L, Nankervis CA, Giannone PJ. Maternal preeclampsia and neonatal outcomes. J Pregnancy. 2011.

19. Liu C-M, Cheng P-J, Chang S-D. Maternal complications and perinatal outcomes associated with gestational hypertension and severe preeclampsia in Taiwanese women. J Formos Med Assoc. 2008;107(2):129-38.

20. Zenebe K, Awoke T, Birhan N. Low birth weight \& associated factors among newborns in Gondar town, north West Ethiopia: institutional based crosssectional study. Indo Glob J Pharm Sci. 2014;4(2):74-80.

21. Xiong X, Demianczuk NN, Saunders LD, Wang F-L, Fraser WD. Impact of preeclampsia and gestational hypertension on birth weight by gestational age. Am J Epidemiol. 2002;155(3):203-9.

22. Wen Y-H, Yang H-I, Chou H-C, Chen C-Y, Hsieh W-S, Tsou K-I, Tsao P-N. Association of Maternal Preeclampsia with neonatal respiratory distress syndrome in very-low-birth-weight infants. Sci Rep. 2019:9(1):1-8.

23. Swanbrow D. Born to lose: How birth weight affects adult health, success. US Fed News Serv, including US State News; 2007.

24. Law CM. Significance of birth weight for the future. In.: BMJ; 2002.

25. Vata PK, Chauhan NM, Nallathambi A, Hussein F. Assessment of prevalence of preeclampsia from Dilla region of Ethiopia. BMC Res Notes. 2015:8(1):816.

26. Shegaze M, Markos Y, Estifaons W, Taye I, Gemeda E. Magnitude and associated factors of preeclampsia among pregnant women who attend antenatal Care Service in Public Health Institutions in Arba Minch town, southern Ethiopia, 2016. Gynecol Obstet (Sunnyvale). 2016;6(419):2161-0932. 1000419.

27. Hassan M, Begum M, Haque SZ, Jahan N, Yasmeen BN, Mannan A, Choudhury K, Rahman H. Immediate outcome of neonates with maternal hypertensive disorder of pregnancy at a neonatal intensive care unit. North Int Med Coll J. 2015:6(2):57-60.

28. World, Health, Organization: WHO recommendations for prevention and treatment of pre-eclampsia and eclampsia. 2011.

29. World Health Organization. Global Nutrition Targets 2025: Low birth weight policy brief. World Health Organization; 2014.

30. Mersha AG, Abegaz TM, Seid MA. Maternal and perinatal outcomes of hypertensive disorders of pregnancy in Ethiopia: systematic review and meta-analysis. BMC Pregnancy Childbirth. 2019;19(1):458. 
31. Asseffa NA, Demissie BW. Perinatal outcomes of hypertensive disorders in pregnancy at a referral hospital, Southern Ethiopia. PloS one. 2019;14(2): e0213240.

32. Gebrehawerya T, Gebreslasie K, Admasu E, Gebremedhin M. Determinants of low birth weight among mothers who gave birth in Debremarkos referral hospital, Debremarkos town, east Gojam, Amhara region, Ethiopia. Neonat Pediatr Med. 2018;4(145):2.

33. Kebede B, Andargie G, Gebeyehu A. Birth outcome and correlates of low birth weight and preterm delivery among infants born to HIV-infected women in public hospitals of Northwest Ethiopia; 2013.

34. Liberati A, Altman DG, Tetzlaff J, Mulrow C, Gøtzsche PC, loannidis JP, Clarke M, Devereaux PJ, Kleijnen J, Moher D. The PRISMA statement for reporting systematic reviews and meta-analyses of studies that evaluate health care interventions: explanation and elaboration. J Clin Epidemiol. 2009;62(10):e1-34

35. Munn Z, Moola S, Lisy K, Riitano D, Tufanaru C. Methodological guidance for systematic reviews of observational epidemiological studies reporting prevalence and cumulative incidence data. Int J Evidence-based Healthcare. 2015;13(3):147-53.

36. Munn Z, Moola S, Lisy K, Riitano D. The Joanna Briggs institute reviewers' manual 2014. In: The systematic review of prevalence and incidence data Adelaide: The Joanna Briggs Institute; 2014.

37. G: R-G. Detecting publication bias in random effects meta-analysis: An empirical comparison of statistical methods; 2006.

38. Selamawit D, Sisay T. Maternal and Perinatal outcomes of pregenancies complecated by preeclampsia/eclampsia at zewditu memorial hospital. Addis Ababa University school of graduate studies faculty of Medicine. 2015.

39. Adane AA, Ayele TA, Ararsa LG, Bitew BD, Zeleke BM. Adverse birth outcomes among deliveries at Gondar University hospital, Northwest Ethiopia. BMC Pregnancy Childbirth. 2014;14(1):90.

40. Lema D. Determinants of low birth weight in Debre Berehan Referal hospital, north Shoa zone, Amhara regional state, Ethiopia (a case-control study). (Doctoral dissertation, Addis Ababa University; 2015.

41. Ekubagewargies DT, Kassie DG, Takele WW. Maternal HIV infection and preeclampsia increased risk of low birth weight among newborns delivered at University of Gondar specialized referral hospital, Northwest Ethiopia, 2017. Ital J Pediatr. 2019;45(1):7

42. Melese MF, Badi MB, Aynalem GL. Perinatal outcomes of severe preeclampsia/eclampsia and associated factors among mothers admitted in Amhara region referral hospitals, north West Ethiopia, 2018. BMC Res Notes. 2019:12(1):1-6.

43. Terefe W, Getachew Y, Hiruye A, Derbew M, Hailemariam D, Mammo D, Muhiye A. Patterns of hypertensive disorders of pregnancy and associated factors at Debre Berhan referral hospital, north Shoa, Amhara region. Ethiop Med J. $2015 ; 53$.

44. Bekela MB, Shimbre MS, Gebabo TF, Geta MB, Tonga AT, Zeleke EA, Sidemo $N B$, Getnet AB. Determinants of Low Birth Weight among Newborns Delivered at Public Hospitals in Sidama Zone, South Ethiopia: Unmatched Case-Control Study. J Pregnancy. 2020;2020.

45. Desta M, Tadese M, Kassie B, Gedefaw M. Determinants and adverse perinatal outcomes of low birth weight newborns delivered in Hawassa University comprehensive specialized hospital, Ethiopia: a cohort study. BMC Res Notes. 2019;12(1):118.

46. Egata AD, Bafa TA. Predictors of low birth weight in newborn delivered in public Hospital of Gurage Zone, southern Ethiopia: a case-control study. Food Nutr Sci. 2019;10(4):428-38.

47. Gebremariam A. Factors predisposing to low birth weight in Jimma hospital south western Ethiopia. East Afr Med J. 2005;82(11):554

48. Lake EA, Olana Fite R. Low birth weight and its associated factors among newborns delivered at wolaita sodo university teaching and referral hospital, southern Ethiopia, 2018. Int J Pediat. 2019;2019.

49. Obsa M, Wolka Woticha E, Girma Weji B, Kassahun Dessu B, Dendir Wolde G, Gebremskel Girmay B, Tamru Bakru E, Belay L, Hussein Gediye M, Gobena Kute N. Neonatal and fetal outcomes of pregnant mothers with hypertensive disorder of pregnancy at hospitals in Wolaita zone, southern Ethiopia. J Midwifery Reprod Health. 2019;7(2):1615-20.

50. Anbesse J, Eyasu M: Maternal and perinatal outcomes of pregnancies complicated by eclampsia at Tikur Anbessa Hospital - A five year retrospective study. Ethiop J Reprod Health. 2014;7(1).
51. Lula G, Tsega A. The association between maternal characteristics and low birth weight delivery among neonates delivered in Gandhi hospital, Addis Ababa: a cross sectional study. J Fam Med Community Health. 2018;5(3):1151.

52. Mulu GB, Gebremichael B, Desta KW, Kebede MA, Aynalem YA, Getahun MB. Determinants of Low Birth Weight Among Newborns Delivered in Public Hospitals in Addis Ababa, Ethiopia: Case-Control Study. Pediatric Health Med Ther. 2020;11:119.

53. Wagnew M, Dessalegn M, Worku A, Nyagero J. Trends of preeclampsia/ eclampsia and maternal and neonatal outcomes among women delivering in addis ababa selected government hospitals, Ethiopia: a retrospective cross-sectional study. Pan Afr Med J. 2016;25(Suppl 2).

54. Seyom E, Abera M, Tesfaye M, Fentahun N. Maternal and fetal outcome of pregnancy related hypertension in Mettu Karl referral hospital, Ethiopia. J Ovarian Res. 2015;8(1):10.

55. Gudeta TA, Regassa TM. Prevalence of Pregnancy Induced Hypertension and Its Bad Birth Outcome among Women Attending Delivery Service. J Pregnancy Child Health. 2017:4(335):1-4

56. Wolde $Z$, Segni $H$, Woldie M. Hypertensive disorders of pregnancy in Jimma University specialized hospital. Ethiop J Health Sci. 2011;21(3).

57. Berhe AK, llesanmi AO, Aimakhu CO, Mulugeta A. Effect of pregnancy induced hypertension on adverse perinatal outcomes in Tigray regional state, Ethiopia: a prospective cohort study. BMC Pregnancy Childbirth. 2020; 20(1):7.

58. Gudu W, Bekele D. A prospective review of eclampsia at a regional hospital, eastern Ethiopia: incidence, clinical correlates, management and pregnancy outcome. Ethiop Med J. 2018;56:125-32.

59. Ethiopian Public Health Institute (EPHI)[Ethiopia] and ICF. Ethiopia mini demographic and health survey 2019: key indicators.

60. Vats K, Paul M. Study of fetal outcome in hypertensive disorders of pregnancy in a ter ary care maternity hospital of Delhi. Interna onal journal of Reproduc on, Contracep on. Obstet Gynecol. 2016;5(11):3773-7.

61. Kiondo P, Tumwesigye NM, Wandabwa J, Wamuyu-Maina G, Bimenya GS, Okong P. Adverse neonatal outcomes in women with pre-eclampsia in Mulago Hospital, Kampala, Uganda: a cross-sectional study. Pan Afr Med J. 2014;17(Suppl 1).

62. Solwayo N, Brian J, Desmond M. Determinants of adverse maternal and perinatal outcomes in severe preeclampsia and eclampsia in a low-resource setting, Mpilo central hospital, Bulawayo, Zimbabwe. BMC Res Notes. 2019; 12(1):298

63. Essa RM, Madian AAEA. Risk factors and pregnancy outcomes among pregnant women with pre-eclampsia. Assiut Sci Nurs J. 2015;3(6):1-14.

64. Sultana A, Koli LNB, Sayeeda S. Clinical study on risk factors and Fetomaternal outcome of severe preeclampsia in Bangabandhu sheikh Mujib Medical University. Chattagram Maa-O-Shishu Hospital Med Coll J. 2018;17(1):23-8.

65. Mooij R, Lugumila J, Mwashambwa MY, Mwampagatwa IH, van Dillen J, Stekelenburg J. Characteristics and outcomes of patients with eclampsia and severe pre-eclampsia in a rural hospital in Western Tanzania: a retrospective medical record study. BMC Pregnancy Childbirth. 2015;15(1):213.

66. Kheir A, Ali R, Kononna A. Neonatal outcome in hypertensive disorders of pregnancy in a tertiary neonatal unit in Sudan; 2014.

67. Abalos E, Cuesta C, Carroli G, Qureshi Z, Widmer M, Vogel J, Souza JP. Pre-eclampsia, eclampsia and adverse maternal and perinatal outcomes: a secondary analysis of the World Health Organization multicountry survey on maternal and newborn health. BJOG Int J Obstet Gynaecol. 2014;121:14-24.

68. Rahman LA, Hairi NN, Salleh N. Association between pregnancy induced hypertension and low birth weight; a population based case-control study. Asia Pac J Public Health. 2008;20(2):152-8.

69. Adu-Bonsaffoh K, Ntumy MY, Obed SA, Seffah JD. Perinatal outcomes of hypertensive disorders in pregnancy at a tertiary hospital in Ghana. BMC Pregnancy Childbirth. 2017;17(1):388.

70. Endalamaw A, Engeda EH, Ekubagewargies DT, Belay GM, Tefera MA. Low birth weight and its associated factors in Ethiopia: a systematic review and meta-analysis. Ital J Pediatr. 2018;44(1):141.

71. Bilano VL, Ota E, Ganchimeg T, Mori R, Souza JP. Risk factors of pre eclampsia/eclampsia and its adverse outcomes in low-and middle-income countries: a WHO secondary analysis. PloS One. 2014;9(3):e91198.

72. Bramham K, Briley AL, Seed P, Poston L, Shennan AH, Chappell LC. Adverse maternal and perinatal outcomes in women with previous 
preeclampsia: a prospective study. Am J Obstet Gynecol. 2011;204(6): 512. e511-9.

73. Su Y-Y, Zhang J-Z, Wang F. Risk factors and adverse outcomes of preeclampsia: a tertiary care centrebased study in China; 2017.

74. Bridwell M, Handzel E, Hynes M, Jean-Louis R, Fitter D, Hogue C, GrandPierre $\mathrm{R}$, Pierre $\mathrm{H}$, Pearce B. Hypertensive disorders in pregnancy and maternal and neonatal outcomes in Haiti: the importance of surveillance and data collection. BMC Pregnancy Childbirth. 2019;19(1):208.

75. de Souza Rugolo LMS, Bentlin MR, Trindade CEP. Preeclampsia: effect on the fetus and newborn. NeoReviews. 2011;12(4):e198-206.

76. Amaral LM, Wallace K, Owens M, LaMarca B. Pathophysiology and current clinical management of preeclampsia. Curr Hypertens Rep. 2017;19(8):61.

\section{Publisher's Note}

Springer Nature remains neutral with regard to jurisdictional claims in published maps and institutional affiliations.

Ready to submit your research? Choose BMC and benefit from:

- fast, convenient online submission

- thorough peer review by experienced researchers in your field

- rapid publication on acceptance

- support for research data, including large and complex data types

- gold Open Access which fosters wider collaboration and increased citations

- maximum visibility for your research: over $100 \mathrm{M}$ website views per year

At $\mathrm{BMC}$, research is always in progress.

Learn more biomedcentral.com/submissions 